\title{
Joint Pricing and Inventory Management of Interbasin Water Transfer Supply Chain
}

\author{
Xue Chen ${ }^{1}$ and Zhisong Chen (D) ${ }^{1,2}$ \\ ${ }^{1}$ Business School, Nanjing Normal University, Qixia District, Nanjing 210023, China \\ ${ }^{2}$ Stern School of Business, New York University, 44 West Fourth Street, New York 10012, NY, USA \\ Correspondence should be addressed to Zhisong Chen; zhisongchen@gmail.com
}

Received 19 June 2020; Revised 7 August 2020; Accepted 19 August 2020; Published 7 September 2020

Academic Editor: Shouwei Li

Copyright (c) 2020 Xue Chen and Zhisong Chen. This is an open access article distributed under the Creative Commons Attribution License, which permits unrestricted use, distribution, and reproduction in any medium, provided the original work is properly cited.

\begin{abstract}
Four game-theoretical decision models without/with backlogging for the interbasin water transfer (IBWT) supply chain considering water delivery loss under joint pricing and inventory management (JPIM) are first developed, analyzed, and compared; then, the corresponding numerical and sensitivity analyses are conducted and compared; finally, the managerial insights and practical implementations are summarized in this paper. The research results indicate that (1) a revenue and cost sharing contract could effectively coordinate the IBWT supply chain and improve the operational performance of the IBWT supply chain under JPIM; (2) the partial backlogging strategy of water demand could effectively improve the operational performance of the IBWT supply chain under JPIM; (3) coordination strategy with partial backlogging is the best strategy for improving the operational performance of the IBWT supply chain under JPIM; (4) reducing water delivery loss rate and operational costs and increasing backlogging ratio are beneficial to improving the operational performance of the IBWT supply chain under JPIM.
\end{abstract}

\section{Introduction}

To alleviate the shortage of water resources in arid and semiarid areas, various kinds of interbasin water transfer (IBWT) projects have been constructed and operated all over the world, such as the South-to-North Water Diversion (SNWD) Project in China, the California State Water Project, the Central Arizona Project and the Colorado River Aqueduct in the US, the Indira Gandhi Canal and the Telugu Ganga Project in India, the Snowy Mountains Scheme in Australia, the North Sinai Development Project in Egypt, and the National Water Carrier in Israel $[1,2]$. In the practical operation management of the IBWT project, the existing rigid water price mechanism for the IBWT project is decoupled from the water supply-demand relationship and cannot effectively exert the regulatory role of the market mechanism and coordinate the interests of all parties involved. Thus, how to optimize pricing to achieve operational performance improvement under a flexible water price mechanism that is linked to the water supply-demand relationship is an urgent problem for the IBWT projects. Furthermore, due to the random water demand, the order quantity may mismatch with water demand. The water demand may be lower than the order quantity, and the holding cost of excess water inventory will thus be incurred; on the contrary, the water demand may be higher than the order quantity, and the shortage cost of excess water demand will thus be incurred. Hence, how to jointly make optimal pricing and inventory decisions to achieve operational performance improvement is also an important issue for the IBWT projects.

From the perspective of supply chain management, the available research has explored the subsidy policy and the operational strategy of the IBWT green supply chain under social welfare maximization [3, 4], the impact of the supply capacity constraint and fairness concern on the operational decisions and outcomes of the IBWT supply chain under random precipitation [5], and the impact of fully/partial backlogging on the operational decisions and outcomes of IBWT green supply chain coordination considering water 
delivery loss under random precipitation [6]. However, the joint pricing-inventory management decisions and operational strategies for an IBWT supply chain considering water delivery loss and partial backlogging are rarely investigated in the current literatures and practices.

Therefore, this paper will try to explore a novelty research issue regarding the operation management of the IBWT supply chain-the joint pricing-inventory management (JPIM) decisions and operational strategies for the IBWT supply chain considering water delivery loss and partial backlogging under random water demand.

In the following sections, the related literatures are reviewed first in Section 2; the theoretical modeling notations and assumptions for a generic IBWT supply chain are defined in Section 3; four game-theoretical decision models for the IBWT supply chain without/with backlogging under joint pricing-inventory management (JPIM) are developed, analyzed, and compared in Section 4; the corresponding numerical and sensitivity analyses for all models are implemented, and the corresponding results are compared in Section 5; the managerial insights and practical implementations are then summarized in Section 6; finally, the theoretical and practical contributions are summarized.

\section{Literature Review}

Currently, the interaction relationships among multiple stakeholders in the IBWT projects are investigated through game theory, such as the water conflict game-theoretical model of the SNWD project [7], game-theoretical model of the IBWT project considering both the water quantity and water quality [8], water allocation option contract for the IBWT projects [9], and incentive-compatible payment design for the SNWD project [10].

Besides, cooperative game theory is applied to achieve Pareto improvement in the IBWT projects, such as the crisp and fuzzy Shapley game model for the IBWT water allocation [11], cooperative game model for the IBWT water allocation [12], IBWT water resource allocation using the least core game [13], and robust multiobjective bargaining game model for the IBWT water resource allocation [14].

Currently, theories and techniques of supply chain management (SCM) have been applied in the IBWT projects to investigate the interactions among multiple stakeholders and develop equilibrium/coordination operational mechanisms, such as optimal pricing and coordination schemes for the SNWD supply chain [15], coordination mechanism based on revenue sharing contract for the SNWD supply chain with strategic customer [16], asymmetric Nash bargaining model for the SNWD supply chain [17], two-echelon water inventory model with inflow forecasting updates in an IBWT project [18], two-tier pricing and allocation schemes for the SNWD supply chain [19], competition intensity in the water supply chain under two contracts [20], power structures for the competitive water supply chains [21], optimal pricing and ordering strategies for dual competing water supply chains under three contracts [22], subsidy policies and operational strategies for the IBWT green supply chain under social welfare maximization [3, 4], impact of the supply capacity constraint and fairness concern on the operational decisions and outcomes of the IBWT supply chain under random precipitation [5], and impact of fully/partial backlogging on the IBWT green supply chain coordination considering water delivery loss under random precipitation [6].

Nevertheless, these existing literatures regarding IBWT supply chain management neither explored the equilibrium/ coordination strategies of the IBWT supply chain under JPIM, nor investigated the impact of the partial backlogging, the choice of operational strategies, and the water delivery loss on the operational performance of the IBWT supply chain. This paper tries to address the shortcomings in the available literatures and explore the operational strategies for an IBWT supply chain without/with partial backlogging under JPIM. An equilibrium decision model and a coordination decision model for the IBWT supply chain without backlogging/with partial backlogging under JPIM are developed, solved, and compared, respectively, to explore the optimal operational strategies and optimal joint pricing and inventory decisions for the IBWT supply chain.

\section{Modeling Notations and Assumptions}

An IBWT distribution system is a typical "embedded" supply chain structure. In this supply chain system, a horizontal water supply system embeds itself in a vertical water distribution system (see Figure 1). In the horizontal water supply system, a local supplier and an external supplier work as a joint IBWT supplier via an efficient cooperation mechanism. Water resources are transferred and supplied by the local supplier from the water source to the external supplier within the trunk channel and then distributed to water resource distributors of all water intakes via river channels and artificial canals. Finally, the water resources are sold by each distributor to the water resource consumers in his/her service region. The water distributor and the corresponding water market in the $i^{\text {th }}$ water intake are indexed by $i=1,2, \cdots, n$. It is assumed that there are $m$ distributors supplied by the local supplier and $n-\mathrm{m}$ distributors supplied by the external supplier.

On this basis, the parameters used in the models are defined as follows:

$c_{d i}=$ the water transfer cost from the $i^{\text {th }}$ water intake to the $i^{\text {th }}$ distributor

$c_{k}=$ the water transfer cost from the $(k-1)^{\text {th }}$ water intake to the $k^{\text {th }}$ water intake within the horizontal supply chain, $k=1,2, \cdots, n$

$\delta_{k}=$ the water delivery loss rate from the $(k-1)^{\text {th }}$ water intake to the $k^{\text {th }}$ water intake within the horizontal supply chain, and $\delta_{k} \in(0,1), k=1,2, \cdots, n$

$c_{\mathrm{fi}}=$ the fixed cost for the $i^{\text {th }}$ water intake of the IBWT supplier

$c_{\mathrm{fl}}=$ the fixed cost for the local supplier, $c_{\mathrm{fl}}=\sum_{i=1}^{m} c_{\mathrm{fi}}$

$c_{\mathrm{fe}}=$ the fixed cost for the external supplier,

$c_{\mathrm{fe}}=\sum_{i=m+1}^{n} c_{\mathrm{fi}}$ 


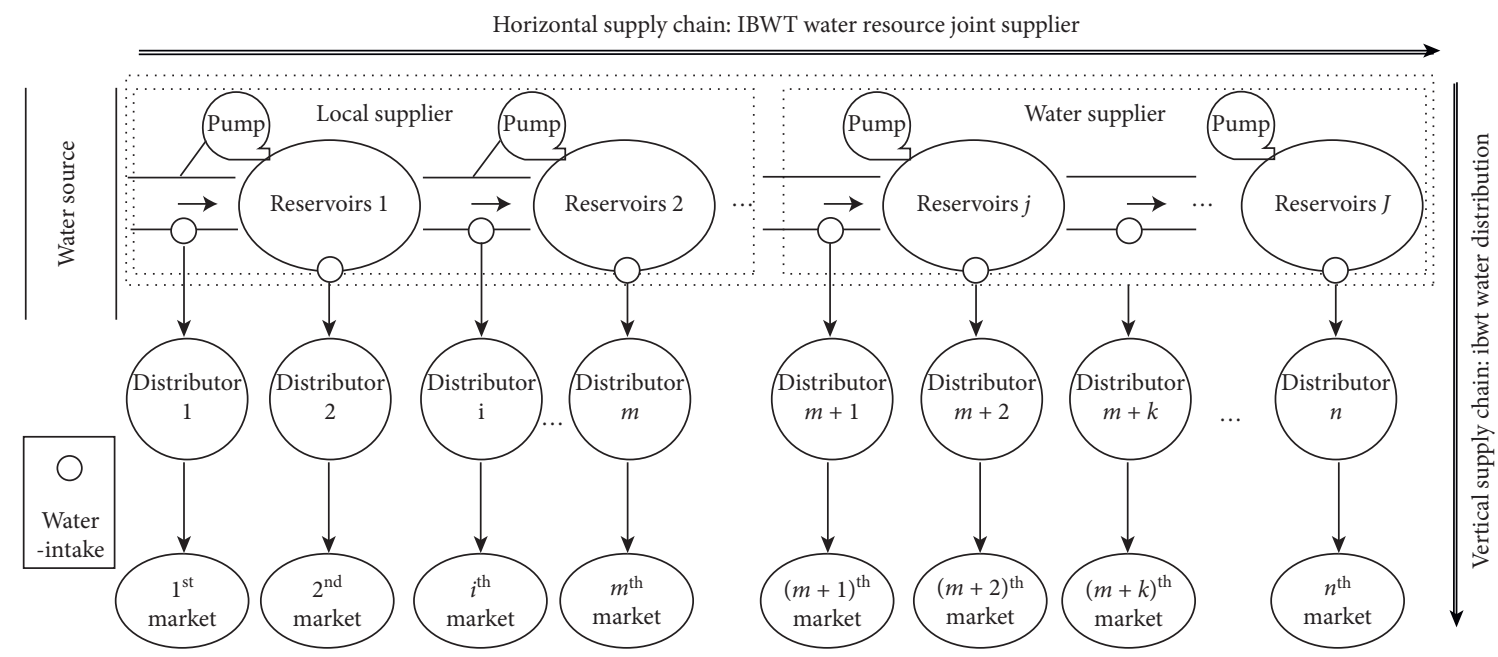

FIgURE 1: A generic interbasin water transfer supply chain system.

$c_{\mathrm{f}}=$ the fixed cost for the IBWT supplier, $c_{\mathrm{f}}=c_{\mathrm{fl}}+c_{\mathrm{fe}}=\sum_{i=1}^{n} c_{\mathrm{fi}}$

$w=$ the wholesale price of water resources transferred from the local supplier to the external supplier

$w_{i}=$ the wholesale price of water resources transferred from the IBWT supplier to the $i^{\text {th }}$ distributor

$p_{i}=$ the retail price of water resources sold from the $i^{\text {th }}$ distributor to the consumers in his service region

$\kappa_{h}=$ the holding cost coefficient, and $0<\kappa_{h}<1$

$h_{i}=$ the unit cost of holding water inventory for the $i^{\text {th }}$ distributor, and $h_{i}=\kappa_{h} p_{i}$

$\kappa_{s}=$ the shortage cost coefficient, and $0<\kappa_{h}<\kappa_{s}<1$

$s_{i}=$ the shortage cost of unmet water demand for the $i^{\text {th }}$ distributor, and $s_{i}=\kappa_{s} p_{i}$

$Q_{i}=$ the original pumping quantity from the water source to the $i^{\text {th }}$ water intake

$q_{i}=$ the order quantity of the $i^{\text {th }}$ water intake

$\tau=$ the bargaining powers of the local supplier, and $\tau \in(0,1)$

$\lambda=$ the bargaining powers of the $i^{\text {th }}$ water intake of the IBWT supplier, and $\lambda \in(0,1)$

As mentioned above, the unmet water demand may be partially backlogged due to the capacity constraint of the IBWT project. The backlogging ratio of unmet water demand for the $i^{\text {th }}$ distributor is $\varphi$, and $\varphi \in[0,1]$. The relationship between the water demand of the $i^{\text {th }}$ water intake $q_{i}$ and the original pumping quantity $Q_{i}$ is $q_{i}=Q_{i} \prod_{k=1}^{i}\left(1-\delta_{k}\right)$, and the total transfer cost of the original pumping quantity $Q_{i}$ is
$\mathrm{TC}_{i}\left(Q_{i}\right)=Q_{i} \sum_{k=1}^{i}\left[c_{k} \prod_{j=0}^{k-1}\left(1-\delta_{j}\right)\right] ; \quad$ hereinto, $\quad \delta_{0}=0$. Therefore, the total transfer cost of the water demand (order quantity) of the $i^{\text {th }}$ water intake is $\operatorname{TC}_{i}\left(q_{i}\right)=\left(\left(\sum_{k=1}^{i}\left[c_{k} \prod_{j=0}^{k-1}\left(1-\delta_{j}\right)\right] / \prod_{k=1}^{i}\left(1-\delta_{k}\right)\right) q_{i}\right) . \quad$ Defining $C_{i}=\left(\sum_{k=1}^{i}\left[c_{k} \prod_{j=0}^{k-1}\left(1-\delta_{j}\right)\right] / \prod_{k=1}^{i}\left(1-\delta_{k}\right)\right)$, then $\mathrm{TC}_{i}\left(q_{i}\right)=C_{i} q_{i}$. Following Howe and Linaweaver [23, 24], Petruzzi and Dada [25], and Wang et al. [26], the water demand for the $i^{\text {th }}$ distributor is $d_{i}\left(p_{i}\right)$, and $d_{i}\left(p_{i}\right)=y_{i}\left(p_{i}\right) x_{i}$. Hereinto, $y_{i}\left(p_{i}\right)=a_{i} p_{i}^{-b}$, where $a_{i}$ is the potential maximum water demand quantity and $b$ is the price elasticity of the expected demand. $x_{i}$ is a random disturbance defined in the range $[A, B]$ with $B>A>0$. The cumulative distribution function $(\mathrm{CDF})$ and the probability density function (PDF) of $x_{i}$ are $F_{i}(\cdot)$ and $f_{i}(\cdot)$, and the mean value and the standard deviation of $x_{i}$ are $\mu_{i}$ and $\sigma_{i}$. Following Petruzzi and Dada [25], Wang et al. [27], and Wang [28], $z_{i}=\left(q_{i} / y_{i}\left(p_{i}\right)\right)$ is defined as the "water stock factor" for the $i^{\text {th }}$ distributor; thus, the order quantity function of water resources for the $i^{\text {th }}$ water intake is $q_{i}=y_{i}\left(p_{i}\right) z_{i}$. The distribution of $x_{i}$ satisfies the IGFR (increasing generalized failure rate) condition: $\left(\mathrm{d} g\left(x_{i}\right) / \mathrm{d} x_{i}\right)>0$, where $g_{i}\left(x_{i}\right) \equiv x_{i}\left(f_{i}\left(x_{i}\right) /\left[1-F_{i}\left(x_{i}\right)\right]\right)$, and there exists a unique solution to the maximal expected problem. Many distributions, such as normal distribution and exponential distribution, satisfy the IGFR condition $[27,29,30]$.

Based on the foregoing modeling notations and assumptions, the profit functions of the $i^{\text {th }}$ distributor, the $i^{\text {th }}$ water intake of the IBWT supplier, and the $i^{\text {th }}$ water intake of the IBWT supply chain with partial backlogging can be formulated as follows: 


$$
\begin{aligned}
\Pi_{D_{i}}\left(z_{i}, p_{i}\right)= & p_{i} y_{i}\left(p_{i}\right) E\left[\min \left\{z_{i}, x_{i}\right\}\right]-\kappa_{h} p_{i} y_{i}\left(p_{i}\right) E\left[\left(z_{i}-x_{i}\right)^{+}\right]+\left\{\varphi\left[p_{i}-\left(w_{i}+c_{d i}\right)\right]-\kappa_{s} p_{i}\right\} y_{i}\left(p_{i}\right) E\left[\left(x_{i}-z_{i}\right)^{+}\right] \\
& -\left(w_{i}+c_{d i}\right) y_{i}\left(p_{i}\right) z_{i}, \\
\Pi_{S_{i}}\left(w_{i}\right)= & \left(w_{i}-C_{i}\right) y_{i}\left(p_{i}\right) z_{i}+\varphi\left(w_{i}-C_{i}\right) y_{i}\left(p_{i}\right) E\left[\left(x_{i}-z_{i}\right)^{+}\right]-c_{f i}, \\
\Pi_{S C_{i}}\left(z_{i}, p_{i}\right)= & p_{i} y_{i}\left(p_{i}\right) E\left[\min \left\{z_{i}, x_{i}\right\}\right]-\kappa_{h} p_{i} y_{i}\left(p_{i}\right) E\left[\left(z_{i}-x_{i}\right)^{+}\right]+\left\{\varphi\left[p_{i}-\left(C_{i}+c_{d i}\right)\right]-\kappa_{s} p_{i}\right\} y_{i}\left(p_{i}\right) E\left[\left(x_{i}-z_{i}\right)^{+}\right] \\
& -\left(C_{i}+c_{d i}\right) y_{i}\left(p_{i}\right) z_{i}-c_{f i} .
\end{aligned}
$$

On this basis, the profit functions of the IBWT supplier, the local supplier, the external supplier, and the IBWT supply chain with partial backlogging can be formulated as follows:

$$
\begin{aligned}
\Pi_{S}\left(w_{i}\right) & =\sum_{i=1}^{n} \Pi_{S_{i}}\left(w_{i}\right), \\
\Pi_{\mathrm{LS}}\left(w_{i}, w\right) & =\sum_{i=1}^{m} \Pi_{S_{i}}\left(w_{i}\right)+w \sum_{i=m+1}^{n} y_{i}\left(p_{i}\right) z_{i}, \\
\Pi_{\mathrm{ES}}\left(w_{i}, w\right) & =\sum_{i=m+1}^{n} \Pi_{S_{i}}\left(w_{i}\right)-w \sum_{i=m+1}^{n} y_{i}\left(p_{i}\right) z_{i}, \\
\Pi_{\mathrm{SC}}\left(z_{i}, p_{i}\right) & =\sum_{i=1}^{n} \Pi_{\mathrm{SC}_{i}}\left(z_{i}, p_{i}\right) .
\end{aligned}
$$

\section{Game-Theoretical Decision Models}

Based on the modeling notations and assumptions in Section 3 , two game-theoretical decision models without backlogging/with partial backlogging for the IBWT supply chain under JPIM considering water delivery loss, including the equilibrium and coordination decision models, are developed, analyzed, and compared in this section. In the models to follow, note that the super/subscript $d$ represents an equilibrium decision; the super/subscript $c$ represents a coordination decision; the super/subscript $o$ represents the scenario without backlogging; the super/subscript $b$ represents the scenario with partial backlogging.

4.1. Game-Theoretical Decision Models without Backlogging. Under the scenario without backlogging, the backlogging ratio of unmet water demand for the $i^{\text {th }}$ distributor is $\varphi=0$. Two game-theoretical decision models of the IBWT supply chain without backlogging under JPIM considering water delivery loss, including the equilibrium and coordination decision models, are developed, analyzed, and compared in this section.

4.1.1. Equilibrium Decision Model without Backlogging. Under this scenario, the detailed decision sequences are as follows: the local and external suppliers will first bargain over the wholesale price of the water resources within the IBWT horizontal supply chain via Nash bargaining theory [32-35] to achieve cooperative operations; then, the IBWT supplier decides the usage price of water resources for each water distributor in the IBWT vertical supply chain; finally, each water distributor independently and simultaneously decides the stock factor and the retail price of water resources for the consumer it serves.

The two-stage Stackelberg and Nash bargaining game model for the IBWT supply chain without backlogging can be formulated as

$$
\begin{aligned}
& \max _{w} \Omega(w)=\left[\Pi_{\mathrm{LS}}^{\mathrm{od}}\left(w_{i}^{\mathrm{od}}, q_{i}^{\mathrm{od}}, w\right)\right]^{\tau}\left[\Pi_{\mathrm{ES}}^{\mathrm{od}}\left(w_{i}^{\mathrm{od}}, q_{i}^{\text {od }}, w\right)\right]^{1-\tau},
\end{aligned}
$$

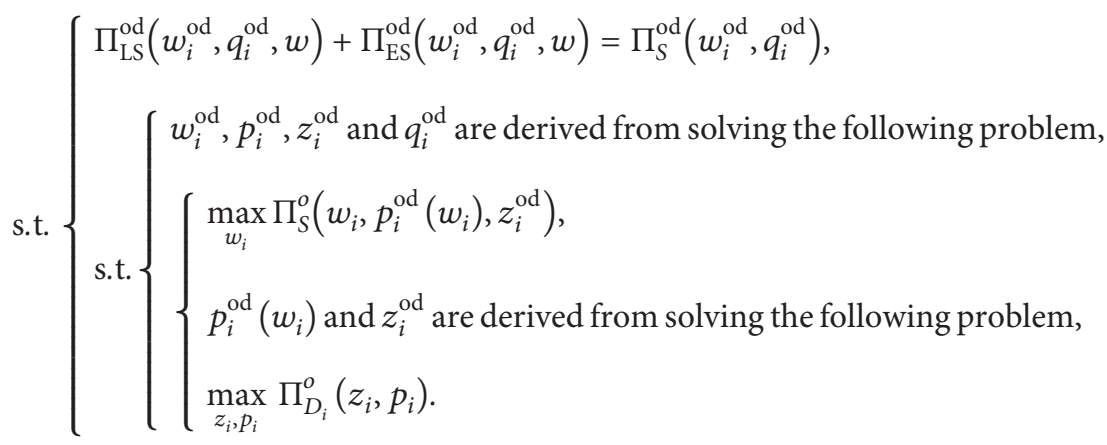


Solving this two-stage Stackelberg and Nash bargaining problem, we can get the equilibrium usage price $w_{i}^{\text {od }}$ in the $i^{\text {th }}$ water intake, the equilibrium retail price $p_{i}^{\text {od }}$ and the equilibrium stock factor $z_{i}^{\text {od }}$ for the $i^{\text {th }}$ water distributor, the equilibrium ordering quantity $q_{i}^{\text {od }}$ for the $i^{\text {th }}$ water distributor, and the bargaining wholesale price $w_{d}^{o}$. Furthermore, the profits of the local supplier, the external supplier, the IBWT supplier, the $i^{\text {th }}$ water distributor, and the IBWT supply chain can be calculated as $\Pi_{\mathrm{LS}}^{\text {od }}, \Pi_{\mathrm{ES}}^{\text {od }}, \Pi_{S}^{\text {od }}, \Pi_{D_{i}}^{\text {od }}$, and $\Pi_{\mathrm{SC}}^{\text {od }}$ (see Table 1 for the detailed analytical results, and their derivations can be seen in sec10Supplementary Materials (available here)).

4.1.2. Coordination Decision Model without Backlogging. Under this scenario, the detailed decision sequences are as follows: the local and external suppliers will first bargain over the wholesale price of water resources within the IBWT horizontal supply chain to achieve cooperative operations; then, the IBWT supplier provides the distributors a revenue sharing contract in which the IBWT supplier charges a lower usage price $w_{i}$ to the water distributors; if the distributors accept the contract, they will place orders with quantity $q_{i}$ to the IBWT supplier and decide the retail price of water resources $p_{i}$ and the stock factor of water resources $z_{i}$; finally, they will share a proportion of their net revenues $(1-\phi)$ to the IBWT supplier, where $\phi$ is the revenue keeping rate of the water distributors, $0 \leq \phi \leq 1$. The revenue shared by the $i^{\text {th }}$ distributor to the IBWT supplier is $T_{i}=$ $(1-\phi) p_{i} y_{i}\left(p_{i}\right)\left\{E\left[\min \left\{z_{i}, x_{i}\right\}\right]-\kappa_{h} E\left[\left(z_{i}-x_{i}\right)^{+}\right]-\kappa_{s} E\left[\left(x_{i}-\right.\right.\right.$ $\left.\left.\left.z_{i}\right)^{+}\right]\right\}$. Thus, the profit functions of the $i^{\text {th }}$ distributor and the IBWT supplier are as follows: $\Pi_{D_{i}}^{\text {oc }}\left(z_{i}, p_{i}\right)=\Pi_{D_{i}}^{o}\left(z_{i}, p_{i}\right)-T_{i}$ and $\Pi_{S}^{\text {oc }}\left(w_{i}\right)=\sum_{i=1}^{n} \Pi_{S_{i}}^{\text {oc }}\left(w_{i}\right)=\sum_{i=1}^{n}\left[\Pi_{S_{i}}^{o}\left(w_{i}\right)+T_{i}\right]$.

The two-stage coordination and Nash bargaining game model for the IBWT supply chain without backlogging can be formulated as

$$
\begin{aligned}
& \max _{w} \Omega(w)=\left[\Pi_{\mathrm{LS}}^{\mathrm{oc}}\left(w_{i}^{\mathrm{oc}}, q_{i}^{\mathrm{oc}}, w\right)\right]^{\tau}\left[\Pi_{\mathrm{ES}}^{\mathrm{oc}}\left(w_{i}^{\mathrm{oc}}, q_{i}^{\mathrm{oc}}, w\right)\right]^{1-\tau}
\end{aligned}
$$

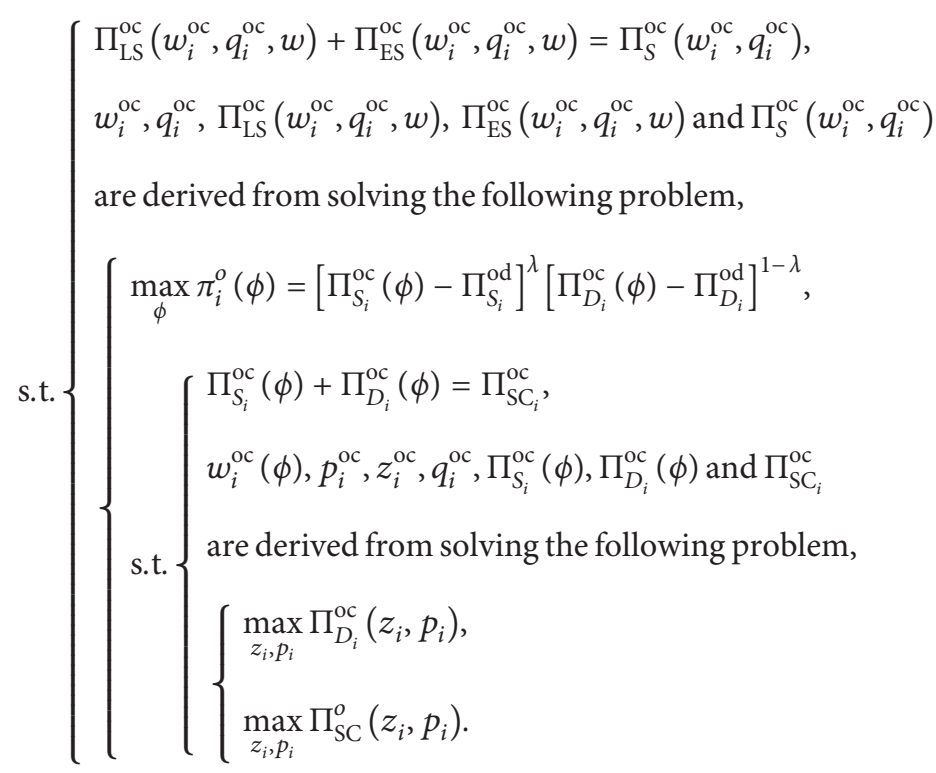

Solving this two-stage coordination and Nash bargaining problem, we can obtain the equilibrium usage price $w_{i}^{\text {oc }}$ in the $i^{\text {th }}$ water intake, the equilibrium retail price $p_{i}^{\text {oc }}$ and the equilibrium stock factor $z_{i}^{\text {oc }}$ for the $i^{\text {th }}$ water distributor, the equilibrium ordering quantity $q_{i}^{\text {oc }}$ for the $i^{\text {th }}$ water distributor, and the bargaining wholesale price $w_{c}^{\text {on }}$. Furthermore, the profits of the local supplier, the external supplier, the IBWT supplier, the $i^{\text {th }}$ water distributor, and the IBWT supply chain can also be computed as $\Pi_{\mathrm{LS}}^{\mathrm{oc}}, \Pi_{\mathrm{ES}}^{\mathrm{oc}}, \Pi_{S}^{\mathrm{oc}}, \Pi_{D_{i}}^{\mathrm{oc}}$, and $\Pi_{\mathrm{SC}}^{\mathrm{oc}}$ (see Table 1 for the detailed analytical results, and their derivations can be seen in Supplementary Materials). 


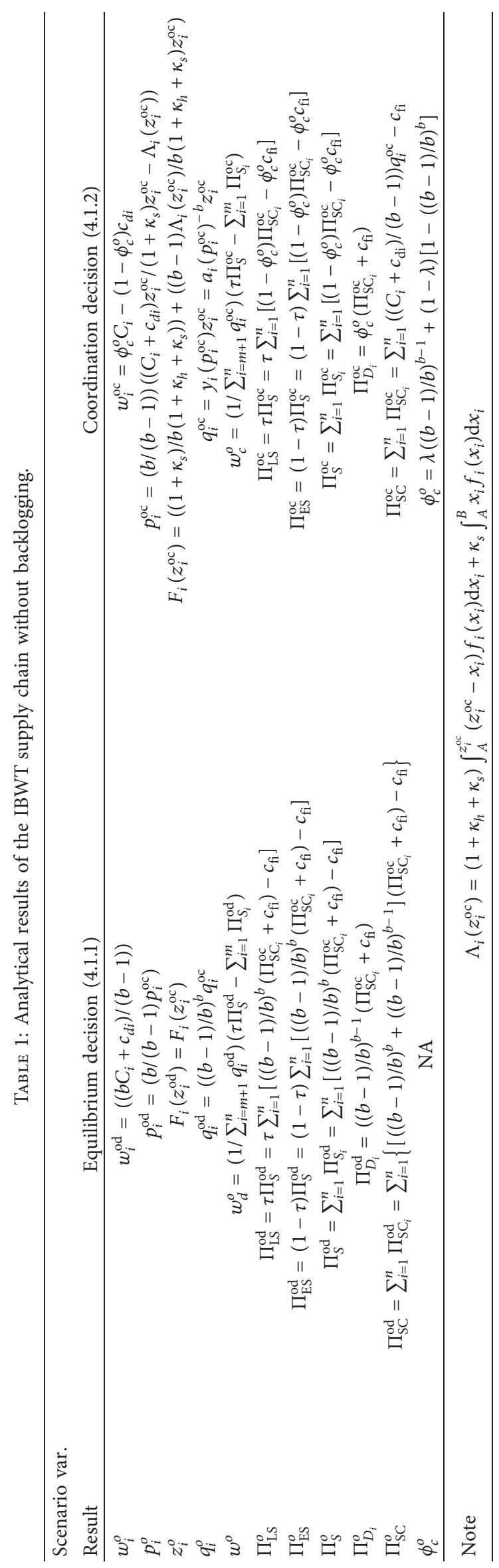


4.2. Game-Theoretical Decision Models with Partial Backlogging. Under the scenario with partial backlogging, the backlogging ratio of unmet water demand for the $i^{\text {th }}$ distributor is $\varphi \in(0,1]$. Two game-theoretical decision models of the IBWT supply chain with partial backlogging under JPIM considering water delivery loss, including the equilibrium and coordination decision models, are developed, analyzed, and compared in this section.

\subsubsection{Equilibrium Decision Model with Partial Backlogging.} Under this scenario, the detailed decision sequences are as follows: the local and external suppliers will first bargain over the wholesale price of the water resources within the IBWT horizontal supply chain to achieve cooperative operations; next, the IBWT supplier decides the usage price of water resources for each water distributor in the IBWT vertical supply chain; then, each water distributor independently and simultaneously decides the stock factor and the retail price of water resources for the consumer it serves; finally, the unmet water demands of each market are partially backlogged and satisfied. The two-stage Stackelberg and Nash bargaining game model for the IBWT supply chain with partial backlogging can be formulated as

$$
\begin{aligned}
& \max _{w} \Omega(w)=\left[\Pi_{\mathrm{LS}}^{\mathrm{bd}}\left(w_{i}^{\mathrm{bd}}, q_{i}^{\mathrm{bd}}, w\right)\right]^{\tau}\left[\Pi_{\mathrm{ES}}^{\mathrm{bd}}\left(w_{i}^{\mathrm{bd}}, q_{i}^{\mathrm{bd}}, w\right)\right]^{1-\tau}
\end{aligned}
$$

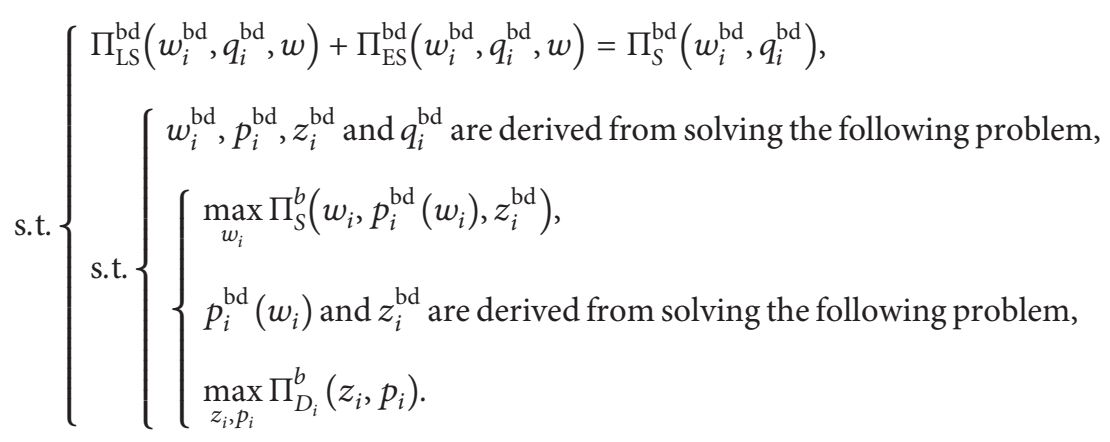

Solving this two-stage Stackelberg and Nash bargaining problem, we can obtain the equilibrium usage price $w_{i}^{\text {bd }}$ in the $i^{\text {th }}$ water intake, the equilibrium retail price $p_{i}^{\text {bd }}$ and the equilibrium stock factor $z_{i}^{\text {bd }}$ for the $i^{\text {th }}$ water distributor, the equilibrium ordering quantity $q_{i}^{\text {bd }}$ for the $i^{\text {th }}$ water distributor, and the bargaining wholesale price $w_{d}^{b}$. Furthermore, the profits of the local supplier, the external supplier, the IBWT supplier, the $i^{\text {th }}$ water distributor, and the IBWT supply chain can be calculated as $\Pi_{\mathrm{LS}}^{\mathrm{bd}}, \Pi_{\mathrm{ES}}^{\mathrm{bd}}, \Pi_{S}^{\mathrm{bd}}, \Pi_{D_{\dot{j}}}^{\mathrm{bd}}$, and $\Pi_{\text {SC }}^{\text {bd }}$ (see Table 2 for the detailed analytical results, and their derivations can be seen in Supplementary Materials).

4.2.2. Coordination Decision Model with Partial Backlogging. Under this scenario, the detailed decision sequences are as follows: the local and external suppliers will first bargain over the wholesale price of water resources within the IBWT horizontal supply chain to achieve cooperative operations; next, the IBWT supplier offers the distributors a revenue sharing contract in which the IBWT supplier charges a lower usage price $w_{i}$ to the water distributors; if the distributors accept the contract, they will place orders with quantity $q_{i}$ to the IBWT supplier and decide the retail price of water resources $p_{i}$ and the stock factor of water resources $z_{i}$; then, the unmet water demands of each market are partially backlogged and satisfied; finally, all the distributors will share a proportion of their net revenues $(1-\phi)$ to the IBWT supplier, where $\phi$ is the revenue keeping rate of the water distributors, $0 \leq \phi \leq 1$. The revenue shared by the $i^{\text {th }}$ distributor to the IBWT supplier is $T_{i}=(1-\phi) p_{i} y_{i}\left(p_{i}\right)$ $\left\{E\left[\min \left\{z_{i}, x_{i}\right\}\right]-\kappa_{h} E\left[\left(z_{i}-x_{i}\right)^{+}\right]-\kappa_{s} E\left[\left(x_{i}-z_{i}\right)^{+}\right]\right\}$. Thus, the profit functions of the $i^{\text {th }}$ distributor and the IBWT supplier are as follows: $\Pi_{D_{i}}^{\mathrm{bc}}\left(z_{i}, p_{i}\right)=\Pi_{D_{i}}^{b}\left(z_{i}, p_{i}\right)-T_{i}$ and $\Pi_{S}^{\mathrm{bc}}\left(w_{i}\right)=\sum_{i=1}^{n} \Pi_{S_{i}}^{\mathrm{bc}}\left(w_{i}\right)=\sum_{i=1}^{n}\left[\Pi_{S_{i}}^{b}\left(w_{i}\right)+T_{i}\right]$.

The two-stage coordination and Nash bargaining game model for the IBWT supply chain with partial backlogging can be formulated as 


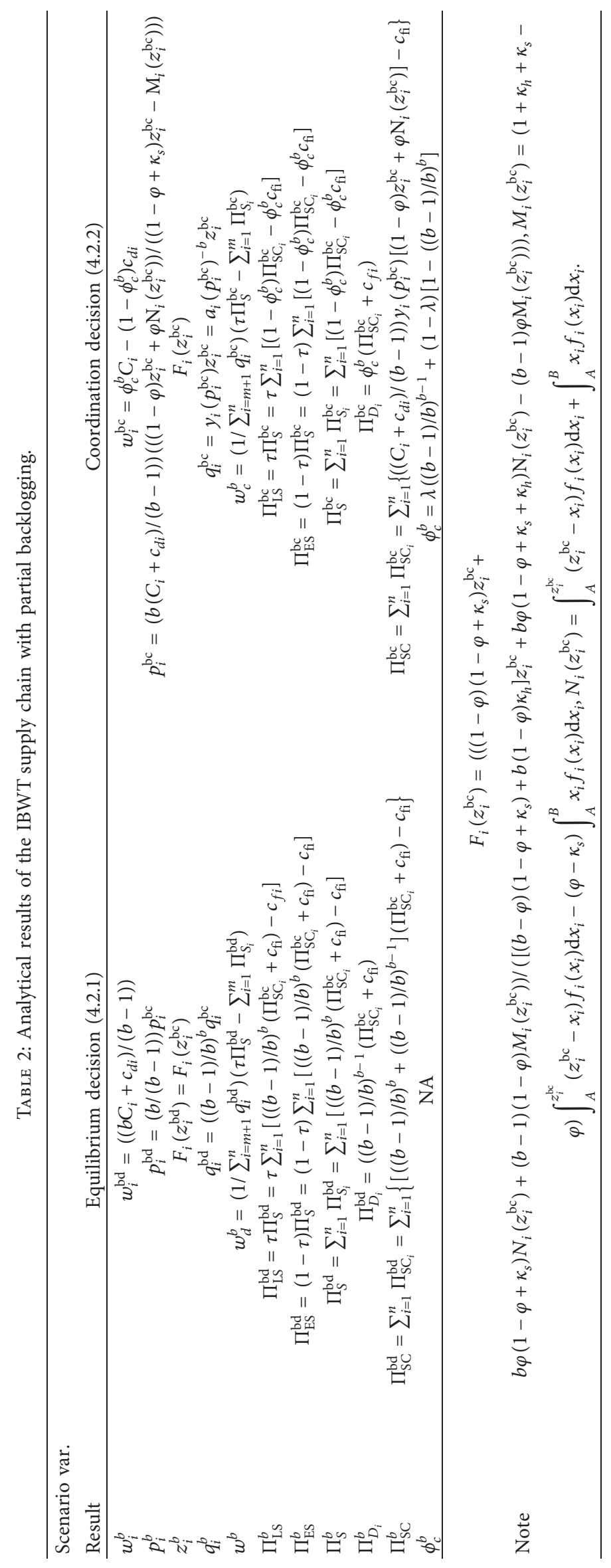




$$
\begin{aligned}
& \max _{w} \Omega(w)=\left[\Pi_{\mathrm{LS}}^{\mathrm{bc}}\left(w_{i}^{\mathrm{bc}}, q_{i}^{\mathrm{bc}}, w\right)\right]^{\tau}\left[\Pi_{\mathrm{ES}}^{\mathrm{bc}}\left(w_{i}^{\mathrm{bc}}, q_{i}^{\mathrm{bc}}, w\right)\right]^{1-\tau}, \\
& \text { s.t. }\left\{\begin{array}{l}
\Pi_{\mathrm{LS}}^{\mathrm{bc}}\left(w_{i}^{\mathrm{bc}}, q_{i}^{\mathrm{bc}}, w\right)+\Pi_{\mathrm{ES}}^{\mathrm{bc}}\left(w_{i}^{\mathrm{bc}}, q_{i}^{\mathrm{bc}}, w\right)=\Pi_{S}^{\mathrm{bc}}\left(w_{i}^{\mathrm{bc}}, q_{i}^{\mathrm{bc}}\right), \\
w_{i}^{\mathrm{bc}}, q_{i}^{\mathrm{bc}}, \Pi_{\mathrm{LS}}^{\mathrm{bc}}\left(w_{i}^{\mathrm{bc}}, q_{i}^{\mathrm{bc}}, w\right), \Pi_{\mathrm{ES}}^{\mathrm{bc}}\left(w_{i}^{\mathrm{bc}}, q_{i}^{\mathrm{bc}}, w\right) \text { and } \Pi_{S}^{\mathrm{bc}}\left(w_{i}^{\mathrm{bc}}, q_{i}^{\mathrm{bc}}\right) \\
\text { are derived from solving the following problem, } \\
\left\{\begin{array}{l}
\max _{\phi} \pi_{i}^{b}(\phi)=\left[\Pi_{S_{i}}^{\mathrm{bc}}(\phi)-\Pi_{S_{i}}^{\mathrm{bd}}\right]^{\lambda}\left[\Pi_{D_{i}}^{\mathrm{bc}}(\phi)-\Pi_{D_{i}}^{\mathrm{bd}}\right]^{1-\lambda}, \\
\prod_{i}^{\mathrm{bc}}(\phi), p_{i}^{\mathrm{bc}}, z_{i}^{\mathrm{bc}}, q_{i}^{\mathrm{bc}}, \Pi_{S_{i}}^{\mathrm{bc}}(\phi), \Pi_{D_{i}}^{\mathrm{bc}}(\phi) \text { and } \Pi_{S C_{i}}^{\mathrm{bc}}, \\
\operatorname{are~derived~from~solving~the~following~problem,~} \\
\prod_{z_{i}, p_{i}}^{\mathrm{bc}}(\phi)=\Pi_{D_{i}}^{\mathrm{bc}}, \\
\max _{z_{i}, p_{i}}^{\mathrm{bc}}\left(z_{i}, p_{i}\right),
\end{array}\right.
\end{array}\right.
\end{aligned}
$$

Solving this two-stage coordination and Nash bargaining problem, we can obtain the equilibrium usage price $w_{i}^{\mathrm{bc}}$ in the $i^{\text {th }}$ water intake, the equilibrium retail price $p_{i}^{\mathrm{bc}}$ and the equilibrium stock factor $z_{i}^{\mathrm{bc}}$ for the $i^{\text {th }}$ water distributor, the equilibrium ordering quantity $q_{i}^{\mathrm{bc}}$ for the $i^{\text {th }}$ water distributor, and the bargaining wholesale price $w_{c}^{b}$. Furthermore, the profits of the local supplier, the external supplier, the IBWT supplier, the $i^{\text {th }}$ water distributor, and the IBWT supply chain can also be computed as $\Pi_{\mathrm{LS}}^{\mathrm{bc}}, \Pi_{\mathrm{ES}}^{\mathrm{bc}}, \Pi_{S}^{\mathrm{bc}}, \Pi_{D_{i}}^{\mathrm{bc}}$, and $\Pi_{\mathrm{SC}}^{\mathrm{bc}}$ (see Table 1 for the detailed analytical results, and their derivations can be seen in Supplementary Materials).

\section{Numerical and Sensitivity Analyses}

Based on the game-theoretical decision modeling analysis, a real-world case of the eastern route of the South-to-North Water Diversion (SNWD) project in China is selected to conduct numerical and sensitivity analyses.

The SNWD project is an important world-scale strategic water resource engineering to solve the water shortage problem in northern China. This project is divided into the eastern route, western route, and middle route. These three routes of the SNWD project can transfer water resources separately from the Yangtze River linking Yangtze River, Huaihe River, Yellow River, and Haihe River to formulate a nationwide water supply system with "Four horizontal and Three vertical, South-North deployment, East-West mutual support."

The eastern route of the SNWD project is constructed and extended based on the north water transfer project in Jiangsu Province. Through the Jiangdu water control project in Yangzhou City, Jiangsu Province, the water is extracted from the main stream of the lower reaches of the Yangtze River and transferred by the Beijing-Hangzhou Grand Canal and its parallel river channels to connect Hongze Lake, Luoma Lake, Nansi Lake, and Dongping Lake. After leaving Dongping Lake, there are two ways to deliver water: one is to the north, passing through the Yellow River through a tunnel near Weishan, and then to Tianjin; the other is to the east, Yantai, and Weihai, via the Jiaodong water transfer branch-line. There are 13 pumping stations in this project with a total length of water transfer mainline at 1466.5 kilometers, a water raising capacity at 65 meters, and a water diversion scale of 14.8 billion cubic meters. The eastern route project provides production and domestic water to the east of Huang-Huai-Hai Plain, Jiaodong area, and BeijingTianjin-Hebei region. In the water supply area, there are 25 cities at prefecture level or above from the Huaihe River, the Haihe River, and the Yellow River Basin.

In the eastern route of the SNWD project, there are six sections for the mainline of the project: Section 1 (Jiangdu Station South of Nansi Lake), Section 2 (Lower Cascade of Nansi Lake), Section 3 (Upper Cascade of Nansi Lake$\sim$ Changgou Pumping Station), Section 4 (Changgou Pumping Station Dongping Lake, including East of Dongping Lake), Section 5 (Dongping Lake Qiutun Sluice in Linqing City), and Section 6 (Qiutun Sluice in Linqing City Datun Reservoir). These six sections can be generalized to six water intakes, i.e., $n=6$. Hereinto, Sections 1-2 are managed and operated by the local supplier (Jiangsu Water Source Co. Ltd), and Sections 3 6 are managed and operated by the external supplier (Shandong Mainline Co. Ltd), i.e., 
$m=2$ and $n-m=4$. There are two water distributors in the service region of the local supplier and four water distributors in the service region of the external supplier.

Based on the real characteristics and management practices of the eastern route of the SNWD project in China [2], the numerical and sensitivity analyses are conducted in the following sections, and the corresponding values of parameters relating to the IBWT supply chain are collected and estimated from the publicly disclosed information of the eastern route of the SNWD project [34] and the water transfer scheme for the eastern route of the SNWD project [36]. The parameters of water transfer costs and fixed costs can be estimated according to the cost accounting method. The parameters of the potential maximum water demand quantity and the price elasticity of the expected demand can be estimated based on the historical operation data. The random distribution and corresponding parameters of the random factor can also be fitted based on the historical operation data. The parameter of the water delivery loss rate can be estimated based on the historical operation data. The parameters of the holding cost coefficient and the shortage cost coefficient can be estimated via the cost accounting method or empirical parameters. The backlogging ratio of unmet water demand can be calculated as total shortage quantity divided by extra supply capacity. The bargaining powers of the local supplier and the $i^{\text {th }}$ water intake of the IBWT supplier can be calculated by the market power evaluation. On this basis, the lower bound of the interval of the random factor $\left(x_{i}\right)$ is set at 0.00001 , and the upper bounds of the interval of the random factor $\left(x_{i}\right)$ is set at 1 , i.e., $A=1 E-5, B=1$. The random factor $x_{i}$ obeys normal distribution, i.e., $x_{i} \sim N\left(\mu_{i}, \sigma_{i}^{2}\right)$. The mean value of the random factor $\mu_{i}$ is set at 0.10 , and the standard deviation of the random factor $\sigma_{i}$ is set at 0.01 . The corresponding parameters of mainline/branch-line water transfer costs and potential maximum water demand quantities are collected and estimated in Table 3. The fixed cost of water delivery for the $i^{\text {th }}$ water intake of the IBWT supplier $c_{\mathrm{fi}}$ is $1,000,000$. According to the empirical parameters, the water delivery loss from the $(i-1)^{\text {th }}$ water intake to the $i^{\text {th }}$ water intake within the horizontal supply chain $\delta_{i}$ is about $15 \%$. The backlogging ratio of unmet water demand for the $i^{\text {th }}$ distributor $\varphi$ is 0.8 . The price elasticity of the expected demand $b$ is 1.5 . The holding cost coefficient $\kappa_{h}$ is 0.2 , and the shortage cost coefficient $\kappa_{s}$ is 0.5 . Owing to the advantage of the local supplier, the local supplier's bargaining power $\tau$ is 0.6. Likewise, due to the advantage of the IBWT supplier, the $i^{\text {th }}$ water intake of the IBWT supplier's bargaining power $\lambda$ is 0.6 .

5.1. Numerical Analysis. The joint pricing-inventory operational decisions and performances for all the game-theoretical decision models without/with backlogging are compared and summarized in Tables $4-7$, respectively. It should be noted that the centralized decision neglects the roles of the members' decisions and therefore is inferior to coordination decision regarding the derived solutions. Thus, the centralized decision model is not shown in the numerical analysis separately. The main findings of the numerical analysis are summarized below:

(1) Comparing the numerical analysis results between equilibrium decision (Table 4) and coordination decision (Table 5) without backlogging under JPIM, the findings are summarized as follows: (i) The wholesale prices of water resources under coordination decision are lower than those under equilibrium decision. (ii) The retail prices of water resources under coordination decision are lower than those under equilibrium decision. (iii) The water stock factors under coordination decision are equal to those under equilibrium decision. (iv) The order quantities of water resources under coordination decision are higher than those under equilibrium decision. (v) The profits of the IBWT supply chain and its members under coordination decision are higher than those under equilibrium decision.

(2) Comparing the numerical analysis results between equilibrium decision (Table 6) and coordination decision (Table 7) with partial backlogging under JPIM, the findings are summarized as follows: (i) The wholesale prices of water resources under coordination decision are lower than those under equilibrium decision. (ii) The retail prices of water resources under coordination decision are lower than those under equilibrium decision. (iii) The water stock factors under coordination decision are equal to those under equilibrium decision. (iv) The order quantities of water resources under coordination decision are higher than those under equilibrium decision. (v) The profits of the IBWT supply chain and its members under coordination decision are higher than those under equilibrium decision.

(3) Comparing the numerical analysis results between the scenario without backlogging (Table 4) and the scenario with partial backlogging (Table 6) under equilibrium decision, the findings are summarized as follows: (i) The wholesale prices of water resources under the scenario with partial backlogging are equal to those under the scenario without backlogging. (ii) The retail prices of water resources under the scenario with partial backlogging are lower than those under the scenario without backlogging. (iii) The water stock factors under the scenario with partial backlogging are lower than those under the scenario without backlogging. (iv) The order quantities of water resources under the scenario with partial backlogging are lower than those under the scenario without backlogging. (v) The profits of the IBWT supply chain and its members under the scenario with partial backlogging are higher than those under the scenario without backlogging.

(4) Comparing the numerical analysis results between the scenario without backlogging (Table 5) and the scenario with partial backlogging (Table 7) under coordination decision, the findings are summarized 
TABle 3: Parameter setting.

\begin{tabular}{lccc}
\hline Section (water intake) $i$ & Mainline water transfer cost $\left(c_{i}\right)$ & Branch-line water transfer cost $\left(c_{d i}\right)$ & Potential maximum water demand $\left(a_{i}\right)$ \\
\hline 1 & 0.32 & 0.08 & $1.796+E 9$ \\
2 & 0.24 & 0.10 & $1.218+E 9$ \\
3 & 0.09 & 0.12 & $1.169+E 9$ \\
4 & 0.14 & 0.76 & $1.941+E 9$ \\
5 & 0.41 & 0.29 & $1.117+E 9$ \\
6 & 0.81 & 0.40 & $1.525+E 9$ \\
\hline
\end{tabular}

TABle 4: Numerical analysis results of equilibrium decision without backlogging.

\begin{tabular}{|c|c|c|c|c|c|}
\hline i & $w_{i}^{\text {od }}$ & $p_{i}^{\text {od }}$ & $q_{i}^{\text {od }}$ & $\Pi_{D_{i}}^{\mathrm{od}}$ & $\Pi_{S}^{\text {od }}$ \\
\hline 1 & 1.29 & 4.52 & $19,687,772$ & $53,921,334$ & $48,147,444$ \\
\hline 2 & 2.38 & 8.17 & $5,492,511$ & $27,196,481$ & $\Pi_{\mathrm{LS}}^{\text {od }}$ \\
\hline 3 & 3.12 & 10.69 & $3,525,446$ & $22,826,460$ & $28,888,466$ \\
\hline 4 & 5.40 & 20.33 & $2,230,602$ & $27,477,799$ & $\Pi_{\mathrm{ES}}^{\mathrm{od}}$ \\
\hline 5 & 6.59 & 22.72 & $1,087,114$ & $14,960,682$ & $19,258,978$ \\
\hline 6 & 10.73 & 36.74 & 721,423 & $16,059,575$ & $\Pi_{\mathrm{SC}}^{\mathrm{od}}$ \\
\hline Sum & NA & NA & $32,744,868$ & $162,442,332$ & $210,589,776$ \\
\hline Note & \multicolumn{5}{|c|}{$z_{i}^{\mathrm{od}}=0.11, w_{d}^{o}=0.51$} \\
\hline
\end{tabular}

TABLE 5: Numerical analysis results of coordination decision without backlogging.

\begin{tabular}{llcccc}
\hline$i$ & $w_{i}^{\text {oc }}$ & $p_{i}^{\text {oc }}$ & $q_{i}^{\text {oc }}$ & $\Pi_{D_{i}}^{\text {oc }}$ & $\Pi_{S}^{\text {oc }}$ \\
\hline 1 & 0.23 & 1.51 & $102,300,667$ & $62,521,086$ & $87,008,602$ \\
2 & 0.45 & 2.72 & $28,539,924$ & $31,533,966$ & $\Pi_{L S}^{\text {oc }}$ \\
3 & 0.60 & 3.56 & $18,318,752$ & $26,466,983$ & $52,205,161$ \\
4 & 0.61 & 7.78 & $11,590,549$ & $31,860,151$ & $\Pi_{\mathrm{ES}}^{\text {oc }}$ \\
5 & 1.25 & 12.25 & $5,648,811$ & $17,346,716$ & $34,803,441$ \\
6 & 2.08 & $\mathrm{NA}$ & $3,748,622$ & $18,620,868$ & $\Pi_{S}^{\text {oc }}$ \\
Sum & $\mathrm{NA}$ & \multicolumn{5}{c}{$170,147,325$} & $188,349,770$ & $275,358,372$ \\
\hline Note & & $z_{i}^{\text {oc }}=0.11, w_{c}^{o}=0.20, \phi_{c}^{o}=0.67$ & \\
\hline
\end{tabular}

TABLE 6: Numerical analysis results of equilibrium decision with partial backlogging.

\begin{tabular}{lccccc}
\hline$i$ & $w_{i}^{\text {bd }}$ & $p_{i}^{\text {bd }}$ & $q_{i}^{\text {bd }}$ & $\Pi_{D_{i}}^{\text {bd }}$ & $\Pi_{S}^{\text {bd }}$ \\
\hline 1 & 1.29 & 4.42 & $19,598,802$ & $55,086,318$ & $49,317,312$ \\
2 & 2.38 & 7.99 & $5,467,690$ & $27,784,068$ & $\Pi_{\mathrm{LS}}^{\text {bd }}$ \\
3 & 3.12 & 10.45 & $3,509,514$ & $23,319,631$ & $29,590,387$ \\
4 & 5.40 & 19.88 & $2,220,522$ & $28,071,464$ & $\Pi_{\mathrm{ES}}^{\text {bd }}$ \\
5 & 6.59 & 22.21 & $1,082,201$ & $15,283,911$ & $19,726,925$ \\
6 & 10.73 & 35.93 & 718,163 & $16,406,546$ & $\Pi_{\mathrm{SC}}^{\text {bd }}$ \\
Sum & $\mathrm{NA}$ & $\mathrm{NA}$ & $32,596,892$ & $165,951,937$ & $215,269,249$ \\
\hline Note & & $z_{i}^{\text {bd }}=0.10, w_{d}^{b}=0.53$ & & \\
\hline
\end{tabular}

as follows: (i) The wholesale prices of water resources under the scenario with partial backlogging are equal to those under the scenario without backlogging. (ii) The retail prices of water resources under the scenario with partial backlogging are lower than those under the scenario without backlogging. (iii) The water stock factors under the scenario with partial backlogging are lower than those under the scenario without backlogging. (iv) The order quantities of water resources under the scenario with partial backlogging are lower than those under the scenario without backlogging. (v) The profits of the IBWT supply chain and its members under the scenario with partial backlogging are higher than those under the scenario without backlogging.

5.2. Sensitivity Analysis. Since, in the previous analysis, coordination decision with partial backlogging is found to be superior to the other decisions without/with partial backlogging, the sensitivity analysis will focus on how the changes in eight key parameters (including the mainline transfer cost, the branch-line transfer cost, the holding cost coefficient, the shortage cost coefficient, the backlogging ratio, the price elasticity of the expected water demand, the 
TABLE 7: Numerical analysis results of coordination decision with partial backlogging.

\begin{tabular}{lccccc}
\hline$i$ & $w_{i}^{\mathrm{bc}}$ & $p_{i}^{\mathrm{bc}}$ & $q_{i}^{\mathrm{bc}}$ & $\Pi_{D_{i}}^{\mathrm{bc}}$ & $\Pi_{S}^{\mathrm{bc}}$ \\
\hline 1 & 0.23 & 1.47 & $101,838,362$ & $63,871,869$ & $89,018,075$ \\
2 & 0.45 & 2.66 & $28,410,950$ & $32,215,265$ & $\Pi_{\mathrm{LS}}^{\mathrm{bc}}$ \\
3 & 0.60 & 3.48 & $18,235,969$ & $27,038,809$ & $53,410,845$ \\
4 & 0.61 & 6.63 & $11,538,171$ & $32,548,497$ & $\Pi_{\mathrm{ES}}^{\mathrm{bc}}$ \\
5 & 1.25 & 11.98 & $5,623,284$ & $17,721,496$ & $35,607,230$ \\
6 & 2.08 & $\mathrm{NA}$ & $3,731,682$ & $19,023,177$ & $\Pi_{S \mathrm{SC}}^{\mathrm{bc}}$ \\
Sum & $\mathrm{NA}$ & \multicolumn{5}{c}{$169,378,417$} & $192,419,112$ & $281,437,186$ \\
\hline Note & & $z_{i}^{\mathrm{bc}}=0.10, w_{c}^{b}=0.20, \phi_{c}^{b}=0.67$ & & \\
\hline
\end{tabular}

water delivery loss rate, and the bargaining power of the $i^{\text {th }}$ water intake of the IBWT supplier) impact the profits under coordination decision with partial backlogging. To capture the impact of the change in key parameters, we only select the parameters from the $1^{\text {st }}$ distributor and the $1^{\text {st }}$ water intake to conduct sensitivity analysis, including the mainline transfer cost and the branch-line transfer cost. Figure 2 (including eight subgraphs) shows the impact of eight key parameters change on the profit of the IBWT supply chain with partial backlogging. The findings from the sensitivity analysis results are summarized as follows: (1) the IBWT supply chain profit decreases as the mainline transfer cost increases; (2) the IBWT supply chain profit decreases as the branch-line transfer cost increases; (3) the IBWT supply chain profit decreases as the holding cost coefficient increases; (4) the IBWT supply chain profit decreases as the shortage cost coefficient increases; (5) the IBWT supply chain profit increases as the backlogging ratio increases; (6) the IBWT supply chain profit decreases as the price elasticity of the expected water demand increases; (7) the IBWT supply chain profit decreases as the water delivery loss increases; (8) the IBWT supplier's profit increases and the distributors' profits decrease as the bargaining power of the $i^{\text {th }}$ water intake of the IBWT supplier increases.

\section{Managerial Insights and Practical Implications}

Based on the foregoing analysis, this section will expound on the managerial insights and practical implications.

6.1. Managerial Insights. Based on the foregoing discussions, the managerial insights can be derived and summarized as follows.

First, be it under the scenario without backlogging or under the scenario with partial backlogging, the IBWT supply chain and its members would make lower retail prices of water resources and order more water resources under the coordination strategy than those under the equilibrium strategy and could gain more profits under the coordination strategy than those under the equilibrium strategy. Hence, the coordination strategy via a revenue and cost sharing contract is beneficial to improving the operational performance for all the stakeholders and coordinate the IBWT supply chain under JPIM.
Second, be it under equilibrium or coordination strategies, the IBWT supply chain and its members would order less water resources under the scenario with partial backlogging than those under the scenario without backlogging and could gain more profits under the scenario with partial backlogging than those under the scenario without backlogging. Hence, partial backlogging of water demand is beneficial to operational performance improvement for all the stakeholders of the IBWT supply chain under JPIM. Furthermore, the higher the backlogging ratio is, the more profits the IBWT supply chain and its members could gain. Thus, increasing the backlogging ratio is beneficial to operational performance improvement for all the stakeholders of the IBWT supply chain under JPIM.

Finally, be it under the scenario without backlogging or under the scenario with partial backlogging, reducing the water delivery loss rate and operational costs (including mainline transfer cost, branch-line transfer cost, holding cost, and shortage cost) is beneficial to operational performance improvement for all the stakeholders of the IBWT supply chain under JPIM. Furthermore, a lower price elasticity of the expected water demand is beneficial to operational performance improvement for all the stakeholders of the IBWT supply chain under JPIM.

In brief, the coordination strategy using a revenue and cost sharing contract with partial backlogging outperforms all the other scenarios/strategies and is the best strategy for improving the operational performance of all the stakeholders in the IBWT supply chain under JPIM.

6.2. Practical Implications. From the practical perspective of the IBWT project operational management, the practical implications can be derived and summarized for the SNWD project as follows.

First, a fixed water price mechanism is implemented in the eastern and middle routes of the SNWD project currently, which cannot directly reflect the linkage effect between water supply and demand and water price. This rigid existing water price mechanism could not effectively exert the regulatory role of the market mechanism and coordinate the interests of all operating entities involved in the operational management of the SNWD project. Thus, it is suggested that some of the water pricing power may be transferred by the government to the main operating entities of the projects to give full play to the regulating role of the 

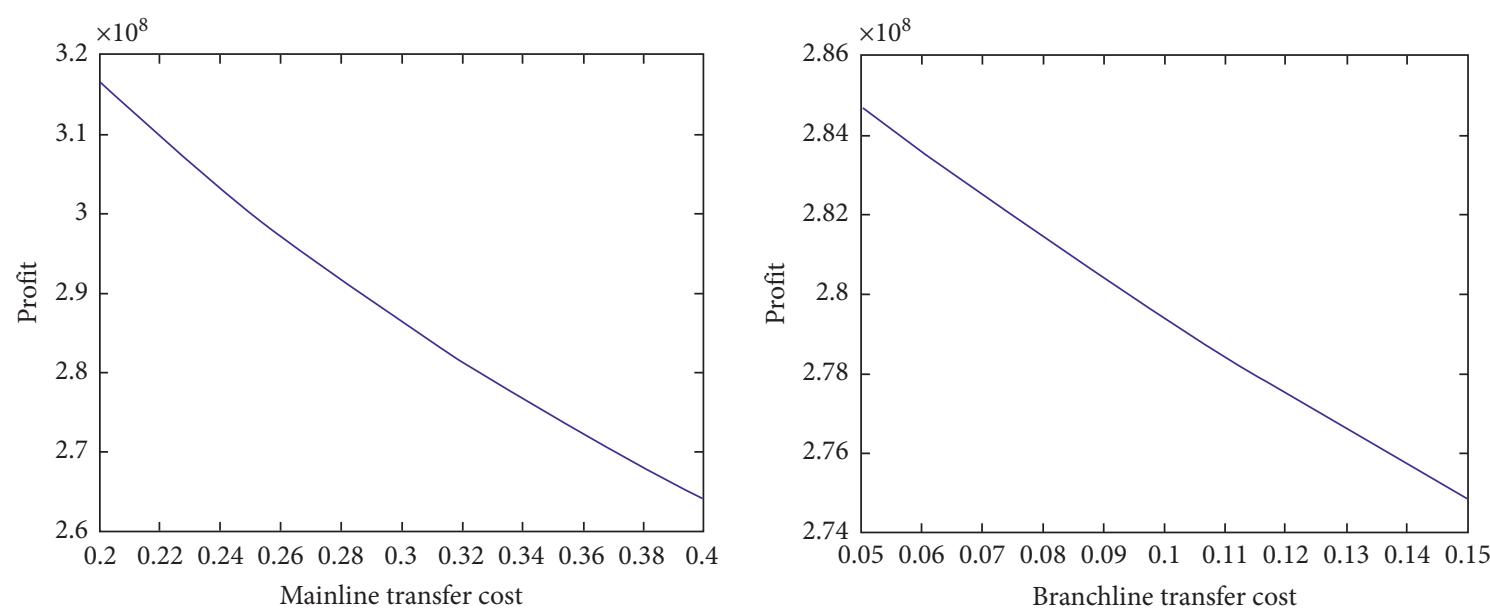

— Supply chain

(a)

— Supply chain

(b)
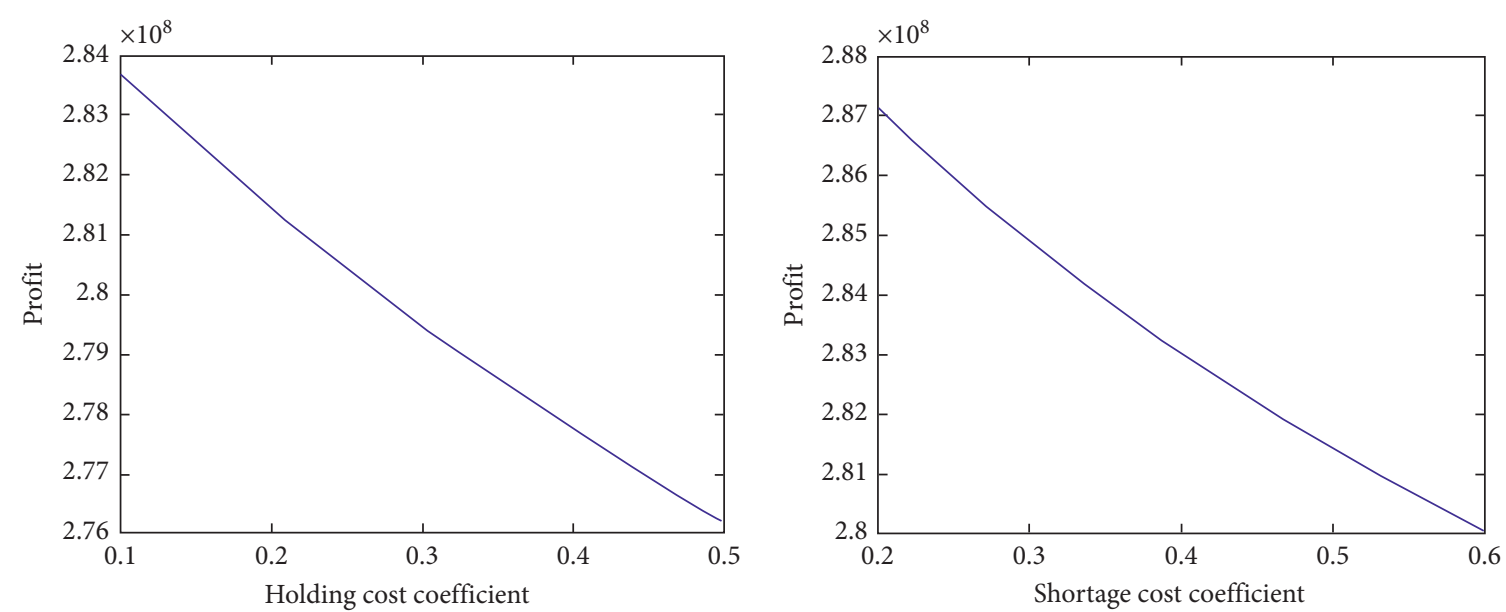

_- Supply chain

(c)

(d)

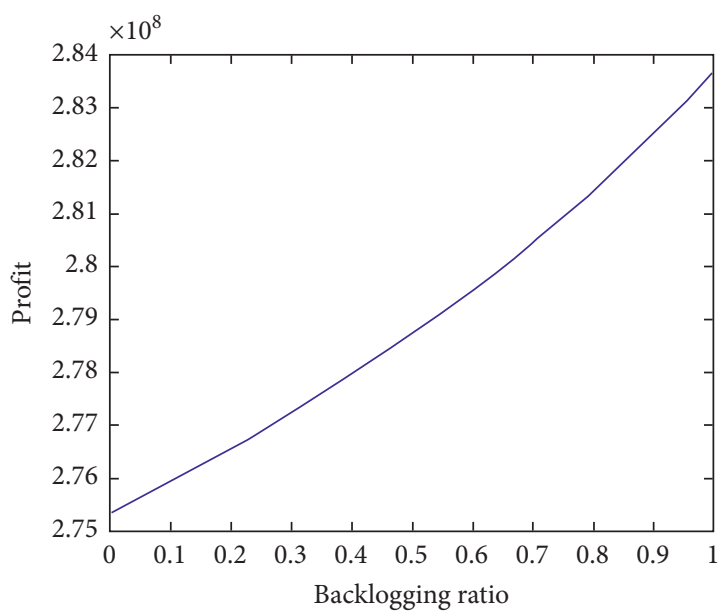

— Supply chain

— Supply chain

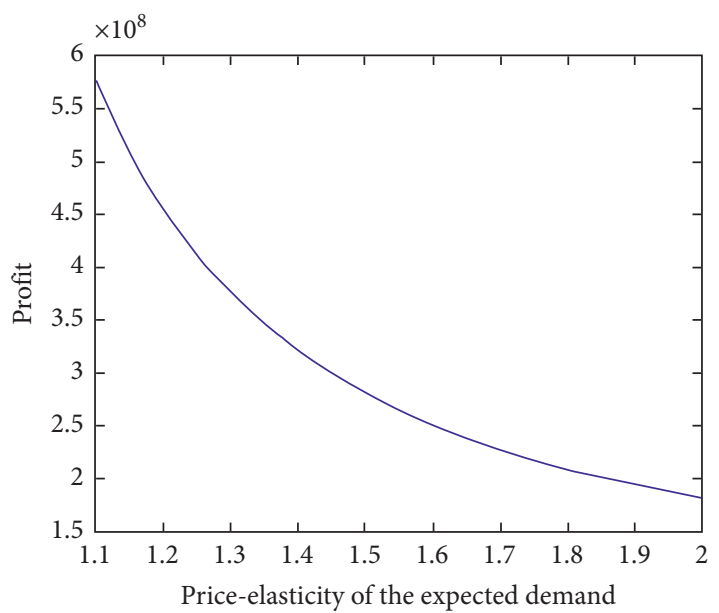

_ Supply chain

(e)

(f)

Figure 2: Continued. 


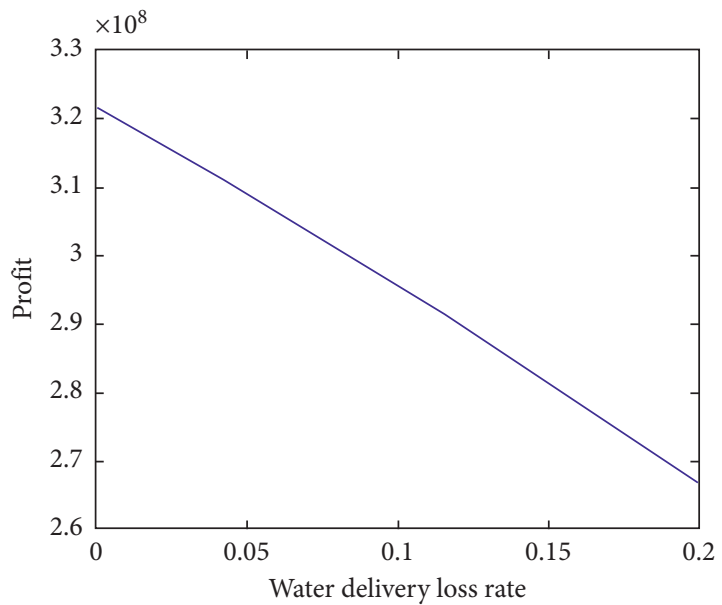

(g)

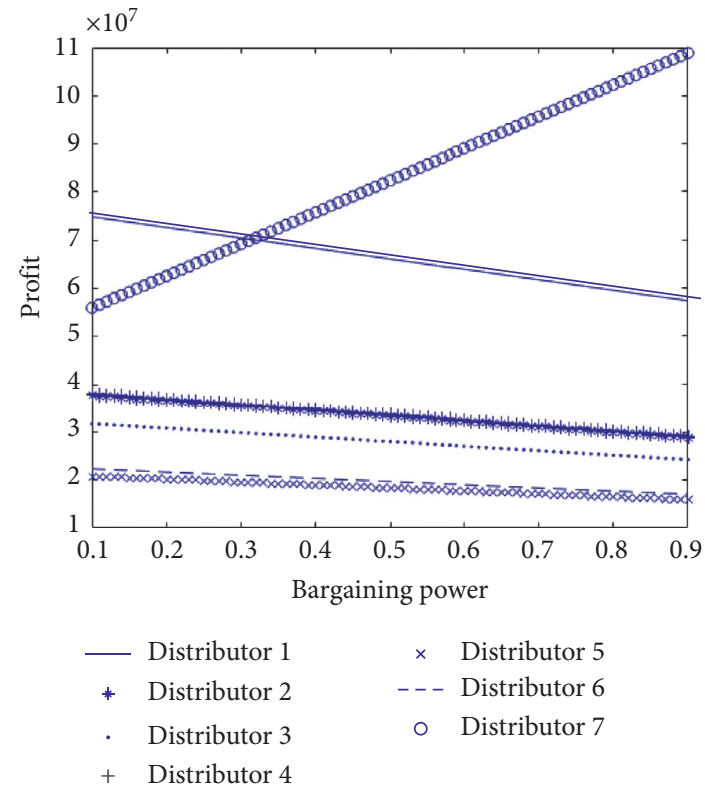

(h)

FIGURE 2: The impact of key parameters' change on the profit of the IBWT supply chain with partial backlogging. (a) Mainline transfer cost; (b) branch-line transfer cost; (c) holding cost; (d) shortage cost; (e) backlogging ratio; (f) price elasticity; (g) water delivery loss rate; (h) bargaining power.

market mechanism. In this situation, the water prices for each water intake and water market in the IBWT project can be adjusted freely according to the relationship between the water supply and demand, which is a flexible water price mechanism. On this basis, a joint pricing and inventory management (JPIM) mode could flexibly reflect the linkage effect between water supply and demand and water price and regulate water supply and demand through the market mechanism and thus is recommended to be considered and implemented in the operational management of the SNWD project.

Second, since the asset rights of the eastern route of the SNWD project belong to different entities, each interest entity will tend to pursue its own interests' maximization and will act in its own ways and lack of collaborative operation, which will eventually lead to the reduction in operation efficiency. Under the JPIM mode, a coordination strategy via the revenue and cost sharing contract with partial backlogging could effectively achieve Pareto improvement of all the stakeholders' interests and thus is recommended to be adopted to coordinate all the stakeholders in the eastern route of the SNWD project. The detailed action sequence of this coordination strategy is as follows: the local and the external suppliers first bargain over the wholesale price of water resources within the IBWT horizontal supply chain to achieve cooperative operations; next, the IBWT supplier provides the distributors a revenue sharing contract in which the IBWT supplier charges a lower usage price to the water distributors; if the distributors accept the contract, they will place orders to the IBWT supplier and decide the retail price of water resources and the stock factor of water resources; then, the unmet water demands of each market are partially backlogged and satisfied; finally, all the distributors' net revenues will be shared to the IBWT supplier.

Finally, the order quantity of water resources mismatching with the random water demand would induce unnecessary losses (including holding cost or shortage cost) in the operational management of the IBWT project. Under the JPIM mode, a partial backlogging strategy could effectively reduce these unnecessary losses and thus is recommended to be adopted in the operational management of the eastern route of the SNWD project. The decision makers of the project should make a lot of effort to enhance their backlogging abilities and increase the backlogging ratio to improve the operational performance of all the stakeholders. Furthermore, water delivery loss and water transfer costs have important impacts on the optimal operational decisions/performance of the project; the decision makers of the project should make a lot of effort to reduce water delivery loss and water transfer costs in the operational management of the project.

In sum, a joint pricing and inventory management (JPIM) mode based on the flexible water price mechanism is recommended to be implemented, and a coordination strategy via the revenue and cost sharing contract with partial backlogging is also recommended to be adopted to improve operational efficiency for the eastern route of the SNWD project.

\section{Conclusions}

From a perspective of supply chain management, this paper tries to explore the issues of joint pricing-inventory 
management decisions and operational strategies for the IBWT project considering water delivery loss and partial backlogging. The equilibrium and coordination decision models without/with partial backlogging for the IBWT supply chain considering water delivery loss under joint pricing and inventory management (JPIM) are developed, analyzed, and compared through a game-theoretical approach, and the corresponding numerical and sensitivity analyses for all models are implemented and compared; finally, the managerial insights and practical implementations are summarized in this paper. The research results show that (1) a revenue and cost sharing contract could effectively coordinate the IBWT supply chain and improve the operational performance of the IBWT supply chain under JPIM; (2) the partial backlogging strategy of water demand could effectively improve the operational performance of the IBWT supply chain under JPIM; (3) coordination strategy with partial backlogging is the best strategy for improving the operational performance of the IBWT supply chain under JPIM; (4) reducing water delivery loss rate and operational costs (including mainline transfer cost, branch-line transfer cost, holding cost, and shortage cost) are beneficial to improving operational performance of the IBWT supply chain under JPIM; (5) increasing the backlogging ratio is beneficial to improving operational performance of the IBWT supply chain under JPIM; (6) a lower price elasticity of the expected water demand is beneficial to improving operational performance of the IBWT supply chain under JPIM.

In terms of theoretical contribution, based on the gametheoretical approach, the equilibrium and coordination decision models with partial backlogging under JPIM considering water delivery loss are developed, analyzed, and compared for the IBWT supply chain, respectively, which have enriched the theories, methodologies, and applications in the optimal operation management of IBWT projects. With regard to practical contribution, the analytical and numerical results provide the IBWT stakeholders a better decision support to make better operational decisions and strategies.

\section{Data Availability}

The data used to support the findings of this study are available from the corresponding author upon request.

\section{Conflicts of Interest}

The authors declare that they have no conflicts of interest to this work.

\section{Acknowledgments}

This work was supported by the National Natural Science Foundation of China (Grant no. 71603125), China Scholarship Council (Grant no. 201706865020), National Planning Office of Philosophy and Social Science (Grant no. 19BJY255), MOE (Ministry of Education in China) Youth Foundation Project of Humanities and Social Sciences
(Grant no. 17YJC790002), China Postdoctoral Science Foundation (Grant no. 2019M651833), Social Science Foundation of Jiangsu Province in China (Grant no. 19GLC003), National Key R\&D Program of China (Grant no. 2017YFC0404600), Natural Science Research Project of Colleges and Universities in Jiangsu Province (Grant no. 15KJB110012), and Young Leading Talent Program of Nanjing Normal University.

\section{Supplementary Materials}

Proofs for analytical results of game-theoretical decision models. (Supplementary Materials)

\section{References}

[1] L. Yang, Foreign Projects of Water Diversion, China Water and Power Press, Beijing, China, 2003.

[2] G. Wang, Q. Ouyang, Y. Zhang, J. Wei, and Z. Ren, World's Water Diversion Project, Science Press, Beijing, China, 2009.

[3] Z. Chen and L. Pei, "Inter-Basin water transfer green supply chain equilibrium and coordination under social welfare maximization," Sustainability, vol. 10, no. 4, p. 1229, 2018.

[4] Z. Chen, S. I. Su, and H. Wang, "Inter-basin water transfer supply chain equilibrium and coordination: a social welfare maximization perspective," Water Resources Management, vol. 33, no. 7, pp. 2577-2598, 2019.

[5] Z. Chen and H. Wang, "Inter-basin water transfer supply chain coordination with the fairness concern under capacity constraint and random precipitation," Marine Economics and Management, vol. 2, no. 1, pp. 1-23, 2019.

[6] Z. Chen and H. Wang, "Inter-basin water transfer green supply chain coordination with partial backlogging under random precipitation," Journal of Water and Climate Change, 2020.

[7] S. Wei, H. Yang, K. Abbaspour, J. Mousavi, and A. Gnauck, "Game theory based models to analyze water conflicts in the middle route of the South-to-North water transfer project in China," Water Research, vol. 44, no. 8, pp. 2499-2516, 2010.

[8] H. D. Manshadi, M. H. Niksokhan, and M. Ardestani, "A quantity-quality model for inter-Basin water transfer system using game theoretic and virtual water approaches," Water Resources Management, vol. 29, no. 13, pp. 4573-4588, 2015.

[9] D. Rey, A. Garrido, and J. Calatrava, "An innovative option contract for allocating water in Inter-Basin transfers: the case of the Tagus-Segura transfer in Spain," Water Resources Management, vol. 30, no. 3, pp. 1165-1182, 2016.

[10] J. Sheng and M. Webber, "Incentive-compatible payments for watershed services along the eastern route of China's SouthNorth water transfer project," Ecosystem Services, vol. 25, pp. 213-226, 2017.

[11] M. Sadegh, N. Mahjouri, and R. Kerachian, "Optimal interbasin water allocation using crisp and fuzzy Shapley games," Water Resources Management, vol. 24, no. 10, pp. 2291-2310, 2010.

[12] M. R. Nikoo, R. Kerachian, and H. Poorsepahy-Samian, “An interval parameter model for cooperative inter-basin water resources allocation considering the water quality issues," Water Resources Management, vol. 26, no. 11, pp. 3329-3343, 2012.

[13] K. Jafarzadegan, A. Abed-Elmdoust, and R. Kerachian, “A fuzzy variable least core game for inter-basin water resources 
allocation under uncertainty," Water Resources Management, vol. 27, no. 9, pp. 3247-3260, 2013.

[14] O. Nasiri-Gheidari, S. Marofi, and F. Adabi, "A robust multiobjective bargaining methodology for inter-basin water resource allocation: a case study," Environmental Science and Pollution Research, vol. 25, no. 3, pp. 2726-2737, 2018.

[15] H. Wang, Z. Chen, and S. I. Su, "Optimal pricing and coordination schemes for the eastern route of the South-toNorth water diversion supply chain system in China," Transportation Journal, vol. 51, no. 4, pp. 487-505, 2012.

[16] Z. Chen and H. Wang, "Optimization and coordination of South-to-North water diversion supply chain with strategic customer behavior," Water Science and Engineering, vol. 5, no. 4, pp. 464-477, 2012.

[17] Z. Chen and H. Wang, "Asymmetric Nash bargaining model for the eastern route of South-to-North water diversion supply chain cooperative operations," Journal of the Chinese Institute of Industrial Engineers, vol. 29, no. 6, pp. 365-374, 2012.

[18] Y. Xu, L. Wang, Z. Chen, S. Shan, and G. Xia, "Optimization and adjustment policy of two-echelon reservoir inventory management with forecast updates," Computers \& Industrial Engineering, vol. 63, no. 4, pp. 890-900, 2012.

[19] Z. Chen, H. Wang, and X. Qi, "Pricing and water resource allocation scheme for the South-to-North water diversion project in China," Water Resources Management, vol. 27, no. 5, pp. 1457-1472, 2013.

[20] W. Du, Y. Fan, and X. Tang, "Two-part pricing contracts under competition: the South-to-North Water Transfer Project supply chain system in China," International Journal of Water Resources Development, vol. 32, no. 6, pp. 895-911, 2016.

[21] W. Du, Y. Fan, and L. Yan, "Pricing strategies for competitive water supply chains under different power structures: an application to the South-to-North water diversion project in China," Sustainability, vol. 10, no. 8, pp. 1-13, 2018.

[22] W. Du, Y. Fan, X. Liu, S. C. Park, and X. Tang, "A game-based production operation model for water resource management: an analysis of the South-to-North Water Transfer Project in China," Journal of Cleaner Production, vol. 228, pp. 14821493, 2019.

[23] C. W. Howe and F. P. Linaweaver Jr., "The impact of price on residential water demand and its relation to system design and price structure," Water Resources Research, vol. 3, no. 1, pp. 13-32, 1967.

[24] K. Schoengold, D. L. Sunding, and G. Moreno, "Price elasticity reconsidered: panel estimation of an agricultural water demand function," Water Resources Research, vol. 42, no. 9, Article ID W09411, 2006.

[25] N. C. Petruzzi and M. Dada, "Pricing and the newsvendor problem: a review with extensions," Operations Research, vol. 47, no. 2, pp. 183-194, 1999.

[26] L. Wang, L. Fang, and K. W. Hipel, "Basin-wide cooperative water resources allocation," European Journal of Operational Research, vol. 190, no. 3, pp. 798-817, 2008.

[27] Y. Wang, L. Jiang, and Z.-J. Shen, "Channel performance under consignment contract with revenue sharing," Management Science, vol. 50, no. 1, pp. 34-47, 2004.

[28] Y. Wang, "Joint pricing-production decisions in supply chains of complementary products with uncertain demand," Operations Research, vol. 54, no. 6, pp. 1110-1127, 2006.

[29] M. A. Lariviere and E. L. Porteus, "Selling to the newsvendor: an analysis of price-only contracts," Manufacturing \& Service Operations Management, vol. 3, no. 4, pp. 293-305, 2001.
[30] M. A. Lariviere, "A note on probability distributions with increasing generalized failure rates," Operations Research, vol. 54, no. 3, pp. 602-604, 2006.

[31] J. F. Nash, “The bargaining problem," Econometrica, vol. 18, no. 2, pp. $155-162,1950$.

[32] E. Kalai and M. Smorodinsky, "Other solutions to Nash's bargaining problem," Econometrica, vol. 43, no. 3, pp. 513-518, 1975.

[33] A. Muthoo, Bargaining Theory with Applications, Cambridge University Press, Cambridge, MA, USA, 1999.

[34] National Development and Reform Commission (NDRC), Notice on the Water Supply Price Policy for the First Phase of the East Line of the South-to-North Water Diversion Project (NDRC Price [2014] No. 30) [EB/OL], 2014, http://www. nsbddx.com/single_detail/300.html.

[35] K. Binmore, A. Rubinstein, and A. Wolinsky, "The Nash bargaining solution in economic modelling," The RAND Journal of Economics, vol. 17, no. 2, pp. 176-188, 1986.

[36] Ministry of Water Resources, Notice on Printing and Distributing the Water transfer Scheme (Trial) for the First Phase of the East Route of the South-to-North Water Transfer Project (Water Resources [2013] No. 466) [EB/OL], 2013, http://www. mwr.gov.cn/zwgk/gknr/202008/t20200803_1430819.html. 